\title{
ФИЛОСОФИЯ
}

DOI: https://doi.org/10.15688/lp.jvolsu.2017.4.1

UDC 1.101

LBC 87.3

\section{ANALYSIS OF BOREDOM IN THE CONTEXT OF THE HISTORY OF PHILOSOPHY}

\author{
Anna A. Korolkova \\ State Institute of Economics, Finance, Law and Technology, Gatchina, Russian Federation
}

\begin{abstract}
The purpose of the present article is to analyze the phenomenon of boredom on the basis of the philosophical works of two German notionalists: Kant and Schopenhauer. The given investigation is inspired by the following questions: what reasons bring to a painful experience of boredom? How free is a contemporary man living in the society of abundance and entertainment from the power of boredom? Is it true that boredom is an absolutely negative phenomenon? The author draws a parallel between the Kantian definition of boredom as an "active idleness" and Schopenhauer's thesis according to which boredom is equivalent to a human's "inability to self-activity". In contrast to Kant and Schopenhauer, Nietzsche reveals a constructive value of boredom for it gives a chance to accumulate the energy of creation. It is interesting to note that Joseph Brodsky in his speech to the Dartmouth College graduates appeals the young men not to be afraid of boredom in order to hit bottom as soon as possible. It should be stressed that Nietzsche and Brodsky find the path toward salvation exactly in the realm that Kant considers the most dangerous. According to Kant boredom "rushes life" producing a gloomy foreboding of slow dying. Sometimes feeling of empty time becomes so depressing that a man, having experienced all the pleasures, decides to suicide. The above considerations testify to the relevance of the present article in terms of its scientific significance as well as its vital value.
\end{abstract}

Key words: Kant, boredom, activity, pleasure, time, human being, creation.

УДК 1.101

ББК 87.3

\section{ИСТОРИКО-ФИЛОСОФСКИЙ АНАЛИЗ СКУКИ}

\section{Анна Александровна Королькова}

Государственный институт экономики, финансов, права и технологий, г. Гатчина, Российская Федерация

Аннотация. Цель данной статьи - проанализировать феномен скуки, взяв за основу тексты И. Канта и А. Шопенгауэра. Историко-философское исследование скуки, предпринятое автором, направлено на разрешение следующих вопросов: какие причины вызывают тягостное переживание скуки? свободен ли современный человек, живущий в обществе развлечения, от власти скуки? насколько справедливо утверждение о том, что скука является исключительно деструктивным явлением? В статье подробно рассматривается, почему отсутствие деятельности, неумеренность в наслаждениях, а также внутренняя пустота вызывают не только скуку, но и угасание воли к жизни. Феномен скуки рассматривается не изолированно, а в контексте более общих философских понятий, таких как деятельность, время и удовольствие.

Анализ работы Канта «Антропология с прагматической точки зрения» позволяет выявить роль деятельного начала в жизни человека, а также критерии подлинной деятельности, достойной человеческого назначе- 
ния. Автор проводит параллель между кантовским определением скуки как «деятельного безделия» и тезисом Шопенгауэра о том, что скука есть неспособность к самодеятельности. Оба немецких философа видят спасение от власти скуки в духовной наполненности, удерживающей человека от пустой траты себя в погоне за сиюминугными наслаждениями. В статье дается аргументированный ответ на вопрос, почему гедоник, отождествляющий счастье и чувственное удовольствие, в итоге приходит к внутреннему опустошению.

Позиция Канта и Шопенгауэра противопоставляется взгляду Ницше, согласно которому созидательный смысл скуки состоит в возможности обрести подлинное Я и накопить энергию творчества. Не случайно Иосиф Бродский в своем обращении к выпускникам Дартмутского колледжа призывает отдаться всецело во власть скуки, не боясь «достать до дна». Интересно, что именно там, где Кант видит главную опасность скуки, Ницше и Бродский усматривают возможность к спасению. Согласно кенигсбергскому философу, скука «торопит жизнь», порождая предчувствие медленной смерти. Иногда ощущение пустого времени становится настолько тягостным, что человек, пресытившись удовольствиями, решает покончить жизнь самоубийством. Ввиду указанных выше причин исследование скуки имеет как научную, так и жизненную ценность.

Ключевые слова: Кант, скука, деятельность, удовольствие, время, человек, творчество.

По мысли Артура Шопенгауэра, существуют два врага человеческого счастья печаль и скука [9, с. 229]. Каждому человеку знакомо мучительное переживание пустоты времени, именуемое скукой, однако знакомое еще не значит познанное. Самые простые вещи нередко оказываются наиболее сложными для изучения, ибо их смысл утаивается за их повседневностью: «Знакомое есть привычное, а привычное труднее всего "познавать", то есть видеть его чужим, отдаленным, "вне нас самих"...» [8, с. 330]. Искусство философа и состоит в том, чтобы остановиться там, где все другие пробегают мимо. Любой способен описать состояние скуки, но выявить причины столь тягостного душевного настроения является задачей более высокого порядка. Что порождает скуку: нужда или избыток? Является ли скука исключительно негативным явлением или же содержит в себе созидательное начало? Насколько современное общество потребления и развлечения освобождает человека от власти скуки? Эти и другие вопросы побудили автора к историко-философскому анализу феномена скуки. Цель данной статьи - исследовать понятие скуки в произведениях двух немецких философов: Иммануила Канта и Артура Шопенгауэра.

В работе «Антропология с прагматической точки зрения» Кант определяет скуку как «деятельное безделие». В своей дефиниции скуки немецкий философ объединяет слова, несущие противоположный смысл, создавая таким образом философский оксюморон. С какой целью автор использует данную риторическую фигуру? Для ответа на этот вопрос осуществим герменевтический анализ слово- сочетания «деятельное безделие». Неожиданное сочетание деятельности и безделия в рамках одной дефиниции сразу же приковывает внимание читателя к этому определению, вызывая желание разгадать терминологическую головоломку. Антиномичность подобной фигуры речи может быть разрешена, если определить условия, при которых деятельность можно назвать безделием. Кант относит к такого рода деятельности бездумное чтение журналов, направленное не на образование, а на развлечение: «Этому деятельному безделию читатели придают вид работы и обманывают себя, считая, что проводят время достойным образом, хотя такое времяпровождение ничуть не лучше, чем то, которое предлагает публике "Journal des Luxus und der Moden"» [5, c. 299].

Приведенный Кантом пример свидетельствует о том, что подлинная деятельность в понимании кенигсбергского мыслителя невозможна без участия разума. Чтение «Журнала роскоши и моды», по мнению Канта, не может насытить думающего человека, так как голова при подобном чтении остается пустой. Очевидно, что история моды как научная дисциплина не входила в предмет кантовских интересов, а пассивное разглядывание картинок, с точки зрения немецкого мыслителя, не способствует развитию ума. Видимо, современная образовательная модель зиждется на иных смысловых ориентирах, чуждых кенигсбергскому гению. Если еще в начале двадцать первого века презентации как способ организации учебных занятий были редкостью, то сейчас лекция, прочитанная без привлечения визуальных рядов, рискует попасть в Крас- 
ную книгу. Введение в преподавание подобных инноваций, наряду с очевидными плюсами, таит в себе и опасность, о которой писал еще Кант. Зрительные образы настолько сильно воздействуют на чувственность, что превращают слушателя в пассивного созерцателя, лишая его автономии мысли и воли. Согласно Канту, ничто так не препятствует формированию зрелой личности, как привычка к инерционному мышлению. Исполним завет немецкого классика и проявим творческую смелость в осмыслении кантовской дефиниции скуки как «деятельного безделия».

Первый вариант прочтения вышеуказанного определения основывался на выявлении особой деятельности, которая лишь формально называется таковой, а по сути является безделием. Однако есть и иная возможность интерпретации, отсылающая нас к опыту отчаяния, когда при отсутствии внешних признаков деятельности человек напряженно ищет свою сущность, пытаясь обрести свое подлинное Я. Сам Кант не развивает эту идею, звучащую, скорее, в духе Кьеркегора, нежели в традициях трансцендентальной аналитики субъекта. Тем более интересно выявить те смыслы, которые автор оставил сокрытыми под покровом слов.

Возможность двойственной трактовки кантовского тезиса приводит нас к необходимости прояснить следующий вопрос: какую деятельность немецкий философ считает достойной человеческого назначения? Обратимся к параграфу 9 «Об обязанностях жизни в отношении душевного состояния» из «Лекций по этике»: «Человек чувствует свою жизнь благодаря действиям, а не благодаря наслаждению жизнью. Чем более мы заняты, тем более мы чувствуем, что мы живем, и тем более мы сознаем нашу жизнь. В бездействии мы не только чувствуем, что жизнь проходит мимо нас, но мы чувствуем даже и некоторую безжизненность. Деятельность, следовательно, необходима нам для поддержания жизни» [6, с. 150]. Данный фрагмент можно назвать одой деятельности, воспевающей способность личности к творческому преобразованию себя и мира.

Кант призывает человека заполнить жизненный путь поступками, чтобы на склоне лет быть «сытым своей жизнью», а не пресыщен- ным ею. К пресыщению и скуке ведут наслаждения, которые очень быстро сменяются страданиями, если человек преступает меру. Забота о поддержании деятельного духа является таким же долгом перед самим собой, как и развитие способностей: «Человек (как разумное существо) сам обязан не оставлять неиспользованными и не давать как бы покрываться ржавчиной свои природные задатки...» [7, с. 465]. Не всякая деятельность, согласно Канту, раскрывает творческий потенциал личности, а только та, источником которой является сам субъект. Не случайно немецкий философ называет подобную активность словом «самодеятельность», отделяя ее от всевозможных форм внешнего принуждения к труду. Идеалом для Канта выступает такая деятельность, которая захватывает человека в единстве всех его способностей. Именно это состояние захваченности является антиподом скуке.

Опасность скуки, по убеждению немецкого мыслителя, состоит в том, что она «торопит жизнь». Если «самодеятельность» вызывает у человека желание продлить наполненное событиями время, то скука, напротив, побуждает к тому, чтобы «оставлять каждый момент времени, в котором мы находимся, и переходить в следующий» [5, с. 299]. Таким образом, скука вызывает предчувствие медленной смерти, в некоторых случаях вырастающее до решения покончить жизнь самоубийством. На этот дьявольский соблазн, таящийся в скуке, указывает и отечественный философ Николай Александрович Бердяев в работе «Самопознание. Опыт философской автобиографии»: «Когда по слабости мир кажется пустым, плоским, лишенным измерения глубины, то скука делается диавольским состоянием, предвосхищением адского небытия» $[5$, с. 63$]$.

И Кант, и Бердяев в своем анализе скуки выходят к более общей философской проблеме времени, а именно пустого времени. Интересно проинтерпретировать кантовские размышления о пустом и заполненном времени в экзистенциальном ключе. Человек как природный феномен есть временное, конечное существо, и вся его жизнь представляет собой не что иное, как «бытие к смерти». Время неотделимо от сущности человека - 
если время пустое, то и жизнь человека пуста, а значит, его сущность не раскрыта. Какое же время следует считать пустым? Обратимся к тексту Канта: «Всякое пустое время - это время, которое нам не нравится, да и как же нам понравится такое время? Наслаждение жизнью не заполняет времени, но оставляет его пустым, а к пустому времени человеческая душа чувствует отвращение, недовольство, омерзение» [6, с. 152]. Пустое время, согласно автору, - это время, не заполненное никаким занятием и по этой причине вызывающее скуку. Примечательно, что немецкое слово «Langeweile», означающее скуку, состоит из двух основ: «lange» - долго и «Weile»- некоторое время. Объединение двух этих смыслов дает нам этимологическую дефиницию скуки как долгого времени. Применим нашу филологическую находку к анализу кантовских рассуждений об особенностях восприятия времени.

Парадокс состоит в том, что люди, которые тяготятся долготою времени в каждом отрезке, переживаемом непосредственно, жалуются на краткость времени, взятого в целом, то есть уже в воспоминании: «Всякий отрезок времени им кажется слишком длинен, поскольку в нем им нечего делать, а если они вновь вспомнят о прошедшем, то они не знают, куда подевалось время» [6, с. 153]. Ход мысли Канта, приведенный в данном пассаже, вызывает реминисценцию с идеей Августина о времени как об измерении души. Согласно средневековому мыслителю, время существует в душе человека как единство памяти, созерцания и ожидания. Временем мы измеряем нашу жизнь, но чем измерить само время? Словно отвечая на этот вопрос блаженного Августина, кенигсбергский философ приходит к следующему выводу: время - это априорная форма чувственности. Этим утверждением Кант опровергает представление о времени как о некой объективной реальности, существующей независимо от субъекта.

Определение времени в качестве априорной формы чувственности позволяет переосмыслить феномен скучающих людей, страдающих из-за длинных дней, но короткой жизни. Источником априорного знания является сам субъект, поэтому время, обладающее априорной природой, существует не где-то вовне, а внутри нас самих. Время выступает своеобразным зеркалом души человека: если душа пуста, то и время оказывается пустым. Согласно Канту, время упорядочивает многообразные чувственные данные по принципу «один после другого». Однако в том случае, когда человек ничем не занят, время словно останавливается, не имея материала для работы. В такие часы человека и посещает гнетущее ощущение скуки. Какие причины вызывают это тягостное переживание и можно ли выработать иммунитет от скуки?

Первая причина, состоящая в отсутствии деятельности, была подробно рассмотрена нами выше в контексте кантовской дефиниции скуки как «деятельного безделия». Анализ этой дефиниции привел нас не только к разграничению подлинной и иллюзорной деятельности, но и к раскрытию феномена времени. Понятие скуки выступило в роли смыслового центра, создавшего вокруг себя семантический треугольник: скука - деятельность время. Однако указанное философское триединство можно расширить до логического квадрата, если ввести в наше аналитическое поле понятие удовольствия. Неумеренность в наслаждениях ведет к пресыщению и скуке, ослабляя не только остроту ощущений, но и в целом интерес к жизни. Почему удовольствие оборачивается неудовольствием, а человек, избегающий страдания, идет прямо ему навстречу?

В «Антропологии с прагматической точки зрения» Кант предостерегает читателя от неразумного вкушения удовольствий, воспевая аскезу в качестве наилучшего способа сохранить бодрость духа и желание жить: «Молодой человек! (я повторяю) полюби свою работу, отказывайся от наслаждений не для того, чтобы отречься от них совсем, а для того, чтобы, насколько это возможно, всегда иметь их перед собой в перспективе! Не притупляй преждевременно восприимчивости к ним, употребляя их [во зло]» [5, с. 304-305]. Вспоминаются известные слова о том, что отложенное удовольствие - это еще не потерянное удовольствие. К сожалению, современный человек, одержимый страхом упустить удовольствие, далек от исполнения этого кантовского завета. В погоне за новизной человек досрочно растрачивает ресурс удоволь- 
ствий, теряя способность радоваться мелочам. Недаром еще эпикурейцы сформулировали принцип «Удовольствие от малого!», помогающий человеку отмерять себе такую долю удовольствия, чтобы оно еще могло увеличиваться.

Ошибочно полагать, будто Кант, вводя строгий контроль над чувствами, умаляет значимость удовольствий в жизни человека. Напротив, позиция Канта свидетельствует о глубоком понимании человеческой природы. Немецкий философ осознает, какой колоссальной силой обладает удовольствие и какая внутренняя работа требуется от человека, не желающего стать рабом наслаждений. Без опыта самообладания невозможно властвовать над своими желаниями, однако именно способность к самоограничению дает возможность испытывать еще большее удовольствие. Отказываясь от сиюминутного наслаждения, философ отнюдь не лишает себя радости жизни, а наоборот, сохраняет себя для еще большей радости. Благодаря искусству мудрого измерения ценностей аскет всегда выбирает большее удовольствие вместо меньшего, не обманываясь тем, что меньшее лежит ближе и не требует усилий.

Кант замечает, что погоня за каждым мигом удовольствия делает жизнь человека разбросанной, поскольку выносит центр души вовне. Гедоник, ставящий превыше всего чувственное наслаждение, в итоге приходит к внутреннему опустошению: «Пресыщенность удовольствием вызывает такое отвратительное состояние, что сама жизнь становится избалованному человеку в тягость...» [5, c. 304]. Причина такого душевного разорения, согласно Канту, состоит в безрассудном поиске все новых видов удовольствия: «пресыщенный человек испытал все виды наслаждения и ничего нового для него уже нет» $[5$, с. 299].

Само по себе желание новизны не является ни нравственным, ни безнравственным - весь вопрос в том, где человек ищет эту новизну. Источник нового знания или переживания может находиться как вовне, так и внутри субъекта. Большинство склонно идти по первому пути, находя в новых друзьях или новых странах возможность избежать скуки и поддержать собственный жизненный тонус.
Нередко подобная страсть к постоянным изменениям превращает человека в бесприютного странника, которому мучительно одиноко и в обществе, и наедине с собой. Иммануил Кант, ни разу не выезжавший за пределы Пруссии, представляет собой яркий антипод экстенсивной стратегии поиска новых ощущений.

Кенигсбергскому гению удалось сохранить энергию жизни даже в преклонном возрасте, не нарушая верности ни любимым людям, ни родной стране. Многие считают кантовский сценарий жизни скучным в то время, как сам Кант вдохновлял современников веселым нравом, оптимистичным духом и умением привнести юношеский задор в любую беседу. Исследователь жизни и учения Канта, Вильгельм Виндельбанд так объясняет особенность немецкого гения: «Потому-то над миром кантовского мышления веет свежее дыхание самобытности. Из недр своего уединения он создает и облекает в оригинальную форму мысли, которые производят переворот в эпохе, и доказывает, что можно знать мир, не видев его - если носишь его в себе» [4, c. 12]. Мир, который немецкий классик носил в самом себе, обладал притягательной силой для окружающих. Завороженные гением Канта, студенты любили обращаться к философу за мудрым жизненным советом. По признанию современников, в неформальной беседе ученый умел создать атмосферу тепла и доверия, попутно расточая тысячи гениальных мыслей.

Внутренняя наполненность, отличавшая Канта, характерна для всех творцов духа, ведь именно эта созидательная сила способна вырвать человека из оков обыденности и освободить от власти скуки. В подтверждение нашего тезиса приведем слова Николая Александровича Бердяева: «Я почти никогда не скучал, мне всегда не хватало времени для дела моей жизни, для исполнения моего призвания. У меня не было пустого времени» [2, c. 62]. Развивая свою мысль, отечественный философ приходит к утверждению спасительной роли творчества в жизни человека: «Нет ничего безнадежнее и страшнее этой пустоты скуки. В тоске есть надежда, в скуке безнадежность. Скука преодолевается лишь творчеством» $[2$, с. 58]. Примечательно, что 
Бердяев считает скуку более опасной, нежели тоску, поскольку скука направлена только на низший мир и не дает человеку сил для творчества. Тоска, напротив, имеет выход в трансцендентное и может пробудить в тоскующем подлинное духовное начало.

Если Бердяев сравнивает скуку с тоской, то Артур Шопенгауэр раскрывает двойной антагонизм скуки и печали. Согласно немецкому философу, вся наша жизнь представляет собой напряженный поиск золотой середины между печалью и скукой. Постоянные колебания между этими двумя полюсами заставляют человека выбирать либо одиночество, либо пошлость, причем выбор определяется мерой духовных сил конкретного человека. Интересно проанализировать, какие два уровня противостояния имеет в виду Шопенгауэр, когда пишет о двойном антагонизме скуки и печали. Объективное противоречие, по мысли автора, обусловлено внешними факторами, субъективное - внутренними: «Именно во внешних отношениях нужда и лишения ведут к печали, обеспеченность же и изобилие - к скуке. Соответственно этому простой народ постоянно борется против нужды, то есть печали, а богатые и знатные заняты непрерывной, часто почти отчаянной борьбой со скукой» [9, с. 229]. Мысль Шопенгауэра о том, что изобилие создает скуку, подкрепляется этимологическим разбором данного понятия.

В латинском языке есть как минимум два слова, выступающих эквивалентном скуки: satietas и taedium. Восстановим то смысловое поле, в котором эти понятия рождены. Так, помимо указанного выше значения скуки, satitetas образует целый шлейф семантических обертонов, среди которых наиболее выразительны следующие: достаточность, изобилие, излишество, пресыщение, отвращение. Перевод латинского термина taedium можно рассматривать как полноценное определение скуки, содержащее в себе причинное обоснование этого феномена: «отвращение вследствие пресыщения». Эта филологическая интермедия позволяет нам выявить те смыслы, которые содержатся в самом языке и открыты для творческих интерпретаций. Сами слова таят в себе мудрость - нужно лишь остановиться, чтобы услышать их Логос.
После того как мы раскрыли внешний антагонизм скуки и печали, рассмотрим, в чем состоит внутренний конфликт. По убеждению Шопенгауэра, подлинным источником скуки является внутренняя пустота, и поэтому только духовная наполненность может оградить человека от скуки: «Человек с богатым внутренним миром, находясь в совершенном одиночестве, получает превосходное развлечение в своих собственных мыслях и фантазиях, тогда как тупицу не оградит от убийственной скуки даже постоянная смена компании, зрелищ, прогулок и увеселений» [9, с. 219]. У автора вышеприведенного размышления есть четкий ответ на вопрос: кто больше всего подвержен скуке? Шопенгауэр называет такого человека нелестным словом «тупица», а вот Кант полагает, что именно неразвитая мыслительная активность освобождает от тягостного ощущения ускользающего времени. Образование может стать как источником самовозрастающего удовольствия, так и причиной душевных страданий, от которых защищен человек необразованный: он просто не осознает, чего он лишен. Приведем любопытную ремарку Канта по этому поводу: «Караибы... могут целыми часами сидеть с удочкой в руках, хотя бы и не было никакой рыбы; отсутствие мыслей - это отсутствие стимула к деятельности, который всегда заключает в себе страдание и от которого караибы избавлены» [5, с. 299].

Позиция Шопенгауэра по вопросу о причинах скуки может быть выражена в следующей формуле: чем больше человеческий дух возвышается над обыденностью и посредственностью, тем меньше в нем остается места для скуки. Логическое развитие этой идеи приводит немецкого философа к такому заключению: «...чем больше кто имеет в себе самом, тем меньше нуждается он во внешнем и тем меньшее также имеют для него значение остальные люди. Таким образом, выдающийся ум ведет к необщительности» [9, c. 231]. Ход мыслей Шопенгауэра заводит нас на очень зыбкую почву, ведь получается, что «гений общения» - это парадокс. Более того, согласно авторской логике, самые общительные из всех людей - негры, поскольку в интеллектуальном отношении они являются самыми отсталыми [9, с. 231]. Этот вывод 
Шопенгауэра, основанный на сведениях из французских газет, и вовсе балансирует на грани расового оскорбления. Что же подтолкнуло немецкого философа к столь радикальному суждению?

Определяя скуку как «страшный застой всех сил во всем организме», Шопенгауэр рассуждает в духе Канта. Так же как и немецкий классик, автор «Афоризмов житейской мудрости» усматривает причину скуки в неспособности к самодеятельности. Следует отметить, что традиция отождествлять счастье и деятельность восходит еще к Аристотелю. В «Никомаховой этике» античный философ дает следующее определение счастью, ставшее основой всей западноевропейской ментальности: «...счастье - это определенного качества деятельность души сообразно добродетели» [1, с. 69]. Если сначала мыслители искали спасение в деятельности, то затем пришлось искать спасение от самой деятельности. Лихорадочный темп жизни превратил людей в «заработавшихся рабов», не способных к самостоятельной организации досуга. Не без горечи Шопенгауэр замечает: «Но что же дает большинству людей досуг? Его заполняет скука и пустота, когда нет чувственных наслаждений или дурачеств» [9, с. 232].

В поиске ответа на вопрос, почему же люди оказываются беспомощными наедине с самими собой, Шопенгауэр переходит от анализа объективного антагонизма скуки и печали к раскрытию субъективных причин человеческих страданий. В процессе размышления над этой темой немецкий философ открывает следующую закономерность: чем ближе человек находится к одному источнику страданий, тем дальше он отстоит от другого. Воспользовавшись знанием о том, что под источниками страданий автор имеет в виду скуку и печаль, можно преобразовать исходную формулу. В раскрытом виде тезис Шопенгауэра будет звучать так: чем менее человек подвержен скуке, тем восприимчивее он к печали, и наоборот, чем более он подвержен скуке, тем меньшую опасность для него представляет печаль. В итоге представитель второй крайности всеми силами будет стараться избегать самого себя как главного виновника скуки, ибо в одиночестве обнажа- ется его собственная пустота. Большинство людей не выдерживает испытания самими собой, оказываясь не в состоянии наполнить радостью собственный досуг: «...большинству же свободное время не дает ничего, кроме субъекта, с которым вовсе нечего делать, который страшно скучает, сам себе в тягость» $[9$, с. 233].

Согласно Шопенгауэру, именно ограниченность духа заставляет людей «торопить жизнь» и рождает желание поскорее убить время вместо того, чтобы наполнить его мыслями и поступками: «Если ограниченные головы так подвержены скуке, то это объясняется тем, что их интеллект служит исключительно только посредником мотивов для их воли» [9, с. 232]. В ситуации отсутствия внешних раздражителей, к числу которых относятся чувственные удовольствия, такие люди мучаются скукой и легко становятся жертвами всевозможных видов зависимости. Азартные игры являются одной из форм подобного времяпровождения, когда человек утрачивает автономность воли и мышления.

В самом начале статьи был поставлен вопрос: свободен ли современный человек, живущий в обществе развлечения, от власти скуки? Предельная рационализация труда, истощенность на работе толкают человека к поиску легких способов разгрузить психику и отдаться во власть иррациональных сил. Устав от вынужденного самоконтроля, человек освобождает свой разум в свободное от работы время, однако свобода быстро превращается в зависимость, так как управлять человеком начинают другие. Под другими здесь понимаются не только люди, но и различные формы зависимости и технологии манипуляции. Шопенгауэр предлагает свое понимание причин этого феномена, объясняя деморализующее влияние азартных игр отказом от возможности овладеть собственным «я». Согласно немецкому философу, карточные игры свидетельствуют о «банкротстве мысли»: «В самом деле, так как у людей нет мыслей, которыми бы они могли обмениваться, они обмениваются картами, стараясь отнять друг у друга гульдены» [9, с. 232-233].

Интересно, что Кант, Шопенгауэр и даже Бердяев рассматривают скуку как исключительно негативное явление, по-своему интер- 
претируя истоки этого душевного состояния. В завершение данной статьи хочется привести альтернативный взгляд мыслителя, который увидел в скуке не только деструктивное, но и созидательное начало. По убеждению Фридриха Ницше, отгонять от себя скуку любым путем - это пошло. Определяя скуку как «безветрие души», немецкий философ считает это состояние необходимым условием накопления сил для творчества. Немецкий философ неожиданным образом объединяет в одну категорию художников, созерцателей и авантюристов, как людей, оценивающих работу не с точки зрения прибыли, а через призму удовольствия: «Скуки они страшатся не столь сильно, как работы без удовольствия: им даже потребна многая скука для лучшего выполнения $u x$ работы» [8, с. 179]. Как Ницше раскрывает секрет их бесстрашия перед скукой?

Согласно автору «Веселой науки», мыслителю не следует бояться скуки: «он должен вынести ее, должен переждать в себе ее действие» [8, с. 179]. Эта идея Ницше позволяет осуществить связь времен и продолжить философский диалог на тему скуки с новым участником, Иосифом Бродским. Удивительно, насколько созвучны размышления Ницше о значении скуки словам отечественного поэта, обращенным к выпускникам Дармутского колледжа: «Когда вас одолевает скука, предайтесь ей. Пусть она вас задавит; погрузитесь, достаньте до дна» [3, с. 84]. Оба мыслителя: и Фридрих Ницше, и Иосиф Бродский - рассматривают состояние скуки как возможность взять люфт в этом непрекращающемся потоке повседневных забот и переосмыслить свой жизненный путь. Скука наравне с отчаянием дает человеку шанс обрести подлинную экзистенцию. Именно поэтому избегать скуки, согласно Ницше, означает избегать встречи с самим собой.

Встреча с идеями Канта, Шопенгауэра, Ницше и Бердяева подарила возможность создать новое полифоническое целое, объединенное лейтмотивом скуки. Этот ведущий музыкальный образ можно было бы передать словами Иосифа Бродского: «Раскройте объятия или дайте себя обнять скуке и тоске, которые в любом случае больше вас» [3, с. 87]. Скука - это окно, распахнув которое человек осознает свою ничтожность перед лицом бесконечности, но, закрыв его, никогда не увидит собственного лица.

\section{СПИСОК ЛИТЕРАТУРЫ}

1. Аристотель. Никомахова этика / Аристотель // Собр. соч. : в 4 т. - М. : Мысль,1983. - Т. 4. - С. 53-294.

2. Бердяев, Н. А. Самопознание / Н. А. Бердяев. - Л. : Лениздат, 1991. - 398 с.

3. Бродский, И. А. Похвала скуке / И. А. Бродский // Похвала скуке : избран. эссе.-СПб. : Лениздат : Книжная лаборатория, 2016. - С. 78-89.

4. Виндельбанд, В. От Канта до Ницше / В. Виндельбанд. - М. : КАНОН-пресс, 1998. - 496 с.

5. Кант, И. Антропология с прагматической точки зрения / И. Кант. - СПб. : Наука, 1999. - 471 с.

6. Кант, И. Лекции по этике / И. Кант. - М. : Республика, 2005. - 431 с.

7. Кант, И. Метафизика нравов : в 2 ч. / И. Кант // Критика практического разума. - СПб. : Наука, 1995. - С. 259-505.

8. Ницше, Ф. Веселая наука / Ф. Ницше // Избранные произведения. - М. : Просвещение, 1993. C. $125-376$.

9. Шопенгауэр, А. Афоризмы житейской мудрости / А. Шопенгауэр // Избранные произведения.Ростов н/Д : Феникс, 1997. - С. 213-419.

\section{REFERENCES}

1. Aristotle. Nikomakhova etika [The Nicomachean Ethics]. Sobr. soch.: $v 4 t$. [Collected Works: in 4 vols.]. Moscow, Mysl Publ., 1983, vol. 4, pp. 53-294.

2. Berdyaev N.A. Samopoznanie [SelfKnowledge: An Essay in Autobiography]. Leningrad, Lenizdat Publ., 1991. 398 p.

3. Brodskiy I.A. Pokhvala skuke [Praise to Boredom]. Pokhlava skuke: izbran. esse [Listening to Boredom: The Selected Essays]. Saint Petersburg, Lenizdat; Knizhnaya Laboratoriya Publ., 2016, pp.78-89.

4. Windelband W. Ot Kanta do Nietzsche [From Kant to Nietzsche]. Moscow, KANON-Press, 1998. $496 \mathrm{p}$.

5. Kant I. Antropologiya s pragmaticheskoy tochki zreniya [Anthropology from a Pragmatic Point of View]. Saint Petersburg, Nauka Publ., 1999. 471 p.

6. Kant I. Lektsii po etike [Lectures on Ethics]. Moscow, Respublika Publ., 2005. 431 p.

7. Kant I. Metafizika nravov: v $2 \mathrm{ch}$. [Groundwork of the Metaphysics of Morals]. Kritika prakticheskogo razuma [Critique of Practical Reason]. Saint Petersburg, Nauka Publ., 1995, pp. 259-505. 


\section{ФИЛОСОФИЯ}

8. Nietzsche F. Veselaya nauka [The Gay Science]. Izbrannye proizvedeniya [Selected Writings]. Moscow, Prosveshhenie Publ., 1993, pp.125-376.

9. Schopenhauer A. Aforizmy zhiteyskoy mudrosti [Essays of Arthur Schopenhauer]. Izbrannye proizvedeniya [Selected Writings]. Rostov-on-Don, Feniks Publ., 1997, pp. 213-419.

\section{Information about the Author}

Anna A. Korolkova, Candidate of Philosophical Sciences, Associate Professor, Department of Social and Legal Sciences and Humanities, State Institute of Economics, Finance, Law and Technology, Roshchinskaya St., 5, 188300 Gatchina, Russian Federation, korolkova-anya@yandex.ru.

\section{Информация об авторе}

Анна Александровна Королькова, кандидат философских наук, доцент кафедры социально-правовых и гуманитарных дисциплин, Государственный институт экономики, финансов, права и технологий, ул. Рощинская, 5, 188300 г. Гатчина, Российская Федерация, korolkova-anya@yandex.ru. 